\title{
Benefit from adrenocorticotrophin in myasthenia gravis
}

\author{
L. A. LIVERSEDGE, G. M. YUILL, I. M. S. WILKINSON, \\ AND J. A. HUGHES
}

From the Department of Neurology, Royal Infirmary, Manchester

\begin{abstract}
SYNOPSIS Twenty-one of 29 patients suffering from myasthenia gravis derived benefit from a short intensive course of adrenocorticotrophin (ACTH). The mean duration of benefit was approximately six months. The best results were obtained in patients with a short history of myasthenia. Transient deterioration during the course of injections was encountered in some cases but necessitated assisted respiration only in patients with severe generalized weakness before treatment.
\end{abstract}

There have now been several reports of the efficacy of short high dosage ACTH therapy in the management of myasthenia gravis (Soffer $e t$ al., 1948; Hellman, 1949; Torda and Wolff, 1951 ; Grob and Harvey, 1952; Freydberg, 1960; von Reis et al., 1965; Grob and Namba, 1966; Osserman and Genkins, 1966; Cape and Utterbuck, 1969; Gibberd et al., 1971; Liversedge, 1971; Namba et al., 1971; Brunner et al., 1972). It is well known that transient deterioration during the course of therapy may occur. The purposes of this brief communication are (1) to review the results obtained by this form of treatment in one neurological centre; (2) to identify patients in whom benefit might be expected; (3) to identify features associated with deterioration during the course of treatment.

TABLE 1

CLINICAL FEATURES OF THE 29 PATIENTS DURING THE STUDY

\begin{tabular}{lcc}
\hline $\begin{array}{l}\text { Age } \\
\text { Sex }\end{array}$ & \multicolumn{2}{c}{$\begin{array}{c}\text { 14-61 years (mean } \\
\text { 15 female, } 14 \text { male }\end{array}$} \\
\hline & Grade & No. of patients \\
Severity of myasthenia before & 1 & 2 \\
treatment* & $2 \mathrm{a}$ & 12 \\
& $2 \mathrm{~b}$ & 2 \\
$\begin{array}{l}\text { Duration of myasthenia before } \\
\text { treatment }\end{array}$ & 2 months-37 years (mean 7 \\
Demonstrable thymic enlargement & 7 patients
\end{tabular}

* Grade 1 = ocular myasthenia, grade $2 \mathrm{a}=$ mild generalized, grade $2 b=$ moderate generalized, grade $3=$ severe generalized myasthenia.

\section{METHODS}

The study concerned 29 inpatients with myasthenia 0 gravis whose clinical features are shown in Table $1 . \stackrel{\circ}{\mathbb{D}}$ Twenty-one patients had a single course of therapy, $\stackrel{\oplus}{\vec{N}}$ five patients had two courses, and three patients had을 multiple courses making a total of 43 courses of $\rightarrow$ treatment. All patients received a five-day course of $D$ high dose ACTH therapy (100-200 units daily intra-O응 muscularly). (Thirteen patients received ACTH gel and 16 patients received Synacthen.) The treatment was conducted in a ward with immediately adjacent facilities for respiratory care. Serum electrolytes and 24 hour urinary electrolytes outputs were monitored for three days before and for five days during the course. To counteract the known sodium retaining and potassium losing effects of $\mathrm{ACTH}$, the patients were given a diet containing only $20 \mathrm{mEq}$ sodium daily with potassium supplements during the five days of treatment.

Careful clinical assessment of the patient's muscular power was carried out before, during, and at intervals after a course of therapy. In view of the widely differing muscular involvement among our cases, the clinical assessment was made firstly on the patient's degree of inability to follow his normal daily routine, and secondly on the examiner's overall impression of the patient's muscular status on examination. The improvement in status relates strictly to a qualitative increase in ability and power, and was not related in any way to the period during which the given improvement was maintained. Thus, good improvement meant that there was a return to normal, or very nearly normal, muscular power and ability to follow normal daily routine. Moderate improvement indicated a substantial increment in 
ability and power-falling well short, however, of a return to normal. Slight improvement indicated increment of small but useful degree in ability and power.

With the exception of the patients who deteriorated during the course of ACTH therapy to the extent of requiring assisted respiration, the daily dose of anticholinesterase therapy was left unaltered. In patients requiring assisted respiration, anticholinesterase therapy was conducted on an ad hoc basis but was never completely discontinued.

\section{RESULTS}

In the 43 courses given to 29 patients improvement occurred after 36 courses $(84 \%)$. The mean duration of improvement was 5.7 months. In the 36 instances of benefit, the improvement was graded as good in 11 , moderate in 13 , and slight in 12 . A really satisfactory response was therefore seen in 11 out of 43 courses of treatment in nine out of 29 patients.

TABLE 2

RELATIONSHIP BETWEEN IMPROVEMENT IN MYASTHENIA PRODUCED BY TREATMENT AND DURATION OF MYASTHENIA AT TIME OF TREATMENT

\begin{tabular}{lccc}
\hline & \multicolumn{3}{c}{ Quality of improvement } \\
\cline { 2 - 4 } & Good & Moderate & Slight \\
\hline $\begin{array}{l}\text { Mean duration of myasthenia } \\
\text { in months }\end{array}$ & 29 & 51 & 81 \\
Number of cases per group & 11 & 13 & 12 \\
\hline
\end{tabular}

TABLE 3

RELATION BETWEEN DURATION OF IMPROVEMENT PRODUCED BY TREATMENT AND DURATION OF MYASTHENIA AT TIME OF TREATMENT

\begin{tabular}{|c|c|c|c|c|}
\hline & \multicolumn{4}{|c|}{ Duration of improvement (months } \\
\hline & $0-1$ & $1-2$ & $2-3$ & $3-24$ \\
\hline $\begin{array}{l}\text { Duration of myasthenia in } \\
\text { months }\end{array}$ & 72 & 65 & 41 & 36 \\
\hline Number of cases per group & 14 & 6 & 8 & 8 \\
\hline
\end{tabular}

There was an inverse relationship between the duration of the myasthenia gravis at the time of treatment and improvement after ACTH treatment. Thus patients whose myasthenia was of short duration obtained the best improvement both in quality (Table 2) and duration (Table 3 ). None of the following factors appeared to have any significant influence on the nature of improvement: sex, age, type or severity of myasthenia, presence of thymic pathology or previous thymectomy, or lack of response to a course of high dose ACTH on a previous occasion.

With regard to deterioration during the course of $\mathrm{ACTH}$, the only factor of relevance was the severity of myasthenia before treatment, in that those more severely affected showed a higher incidence of deterioration (Table 4). From Table 4 it can also be seen that types IIB and III were the vulnerable groups for deterioration severe enough to necessitate assisted respiration. No significant influence of the following features was found in relation to the occurrence of deterioration during the course of treatment:

TABLE 4

RELATIONSHIPS BETWEEN DETERIORATION DURING TREATMENT AND SEVERITY OF MYASTHENIA AT TIME OF TREATMENT

\begin{tabular}{lcccc}
\hline & \multicolumn{4}{c}{ Grade of myasthenia* } \\
\cline { 2 - 5 } & 1 & $2 a$ & $2 b$ & 3 \\
\hline Patients deteriorating during & & & & \\
treatment & 0 & 17 & 67 & 100 \\
$\quad \%$ & $0 / 2$ & $3 / 18$ & $14 / 21$ & $2 / 2$ \\
$\quad$ No. & & & & \\
$\begin{array}{l}\text { Patients deteriorating during } \\
\text { treatment necessitating }\end{array}$ & & & & \\
assisted respiration & 0 & 0 & 19 & 50 \\
$\quad \%$ \\
No. & $0 / 2$ & $0 / 18$ & $4 / 21$ & $1 / 2$ \\
\hline
\end{tabular}

* Grade $1=$ ocular myasthenia, grade $2 a=$ mild generalized, grade $2 b=$ moderate generalized, grade $3=$ severe generalized myasthenia.

sex, age, duration of myasthenia, presence of thymic pathology or previous thymectomy, deterioration in a previous course of $\mathrm{ACTH}$, sodium balance or serum potassium during the five days of treatment (potassium balance was not performed).

Particular attention was paid to the state of sodium and potassium metabolism during the course of ACTH. As indicated above, no relationship between improvement after the course or deterioration during the course could be 
TABLE 5

ELECTROLYTE DATA DURING THE FIVE-DAY COURSE OF ACTH TREATMENT

\begin{tabular}{lcc}
\hline & $\begin{array}{c}\text { Patients who } \\
\text { deteriorated }\end{array}$ & $\begin{array}{c}\text { Patients who did } \\
\text { not deteriorate }\end{array}$ \\
\hline Mean values for the five days & & \\
$\quad$ Sodium intake (mEq) & 100 & 100 \\
Sodium output (mEq) & 175 & 231 \\
Sodium balance (mEq) & -75 & -131 \\
Lowest serum potassium (mEq/1.) & $3 \cdot 8$ & 3.9 \\
Mean serum potassium (mEq/l.) & $4 \cdot 1$ & $4 \cdot 3$ \\
\hline
\end{tabular}

found with changes in the sodium or potassium metabolism. From Table 5 it can be seen that the restriction of sodium intake resulted in a virtually neutral sodium balance. The sodium intake of $20 \mathrm{mEq}$ per day almost matched the 24 hour urinary output of sodium. Both the patients who deteriorated and those who did not, experienced the same very minor degree of negative sodium balance, -75 and $-131 \mathrm{mEq}$ sodium in five days respectively. Potassium balance studies were not performed, though Table 5 indicates that there was no significant difference in either the lowest serum potassium or mean serum potassium in patients who deteriorated and in those who did not. Significant hypokalaemia was never seen in any patient, reflecting the efficiency of potassium supplementation.

\section{DISCUSSION}

Because of the really favourable response to treatment in 11 out of 43 courses of ACTH (nine out of 29 patients) we feel that this form of treatment has a definite place in the management of myasthenia gravis. This incidence of good response to treatment is similar to the experience of others. Namba et al. (1971) in their review of the world literature give a figure of 105 out of 251 courses (54 out of 166 patients), though comparison between patients from different centres clearly cannot be absolute since the criteria for using ACTH must vary from centre to centre.

There are some minor points of variance between our results and those reviewed by Namba et al. (1971) but the most significant difference is that the best response in our group was obtained in patients with a short duration of myasthenia, whereas other workers have found a better response in patients who have had the disease for over two years. We feel it is important to make this point after a fruitless search for other features which might help to predict which patients have a favourable response to ACTH treatment. The only feature of such significance in our group of patients was a short history of the disease at the time of treatment.

The occurrence of deterioration during the course of ACTH treatment was rather lower in our series, 19 out of 43 courses $(43 \%)$ ) compared with a figure of $62 \%$ in the world series reviewed by Namba et al. (1971). There are obviously many possible reasons for this numerical difference-for example, type and grade of myasthenia, duration, and dosage of ACTH therapy, etc. For general medical reasons, we feel that sodium restriction and potassium supplementation are indicated during the course of high dose ACTH. In this way the chances of sodium retention with oedema and hypertension and of significant hypokalaemia, are minimized. We were interested to see if careful control of sodium and potassium metabolism during the course of treatment in any way $\stackrel{\circ}{\circ}$ influenced the occurrence of deterioration. As 2 mentioned our deterioration rate was fairly low. This could be attributable to the sodium restriction and potassium supplementation which allo our patients received during the course of treat-? ment, though it must be stated that some patients in our group did deteriorate during the ACTH therapy without any observed change in sodium balance or serum potassium levels. We were unable to detect any significant difference in sodium and potassium metabolism between the patients who deteriorated and those who did not.

The only factor we could identify which correlated positively with the occurrence of deterioration during the course of ACTH therapy was the severity of the myasthenia at the start of treatment. It is clearly important that respiratory care facilities should be available when treating patients with myasthenia by ACTH, especially when the clinical picture is one of severe affection.

\section{REFERENCES}

Brunner, N. G., Namba, T., and Grob, D. (1972). Corticosteroids in management of severe, generalized myasthenia gravis. Neurology (Minneap.), 22, 603-610. 
Cape, C. A., and Utterback, R. A. (1969). Treatment of myasthenia gravis with adrenocorticotrophic hormone (ACTH): massive short-term and maintenance treatment. Journal of Neurology, Neurosurgery, and Psychiatry, 32, 290-296.

Freydberg, L. D. (1960). The place of corticotropin in the treatment of myasthenia gravis. Annals of Internal Medicine, 52, 806-818.

Gibberd, F. B., Navab, F., and Smith, C. L. (1971). Treatment of ocular myasthenia with corticotrophin. Journal of Neurology, Neurosurgery, and Psychiatry, 34, 11-13.

Grob, D., and Harvey, A. M. (1952). Effect of adrenocorticotrophic hormone (ACTH) and cortisone administration in patients with myasthenia gravis and report of onset of myasthenia gravis during prolonged cortisone administration. Bulletin of the Johns Hopkins Hospital, 91, 124-136.

Grob, D., and Namba, T. (1966). Corticotropin in generalized myasthenia gravis. Effect of short, intensive courses. Journal of the American Medical Association, 198, 703-707.

Hellman, L. (1949). Adrenal cortical function and the effect of adrenocorticotropin in myasthenia gravis. Federation Proceedings, 8, 72.
Liversedge, L. A. (1971). Short-term intensive corticotrophin treatment in myasthenia gravis. Proceedings of the Royal Society of Medicine, 64, 492.

Namba, T., Brunner, N. G., Shapiro, M. S., and Grob, D. (1971). Corticotropin therapy in myasthenia gravis: effects, indications, and limitations. Neurology (Minneap.), 21, 1008-1018.

Osserman, K. E., and Genkins, G. (1966). Studies in myasthenia gravis. Short-term massive corticotropin therapy. Journal of the American Medical Association, 198, 699-702.

Reis, G. von, Liljestrand, A.., and Matell, G. (1965). Results with ACTH and spironolactone in severe cases of myasthenia gravis. Acta Neurologica Scandinavica, 41 (Suppl. 13), 463-471.

Soffer, L. J., Gabrilove, J. L., Laqueur, H. P., Votterra, M., Jacobs, M. D., and Sussman, M. L. (1948). The effects of anterior pituitary adrenocorticotropic hormone (ACTH) in myasthenia gravis with tumor of the thymus. Journal of the Mount Sinai Hospital, 15, 73-82.

Torda, C., and Wolff, H. G. (1951). Effects of administration of the adrenocorticotropic hormone (ACTH) on patients with myasthenia gravis. Archives of Neurology and Psychiatry, 66, 163-170. 